\title{
THE SEROLOGICAL RESPONSE TO ASPERGILLUS FUMI- GATUS IN EXPERIMENTAL MYCOTIC ABORTION IN SHEEP
}

\author{
M. J. Corbel, G. A. Pepin and P. G. Millar \\ Ministry of Agriculture, Fisheries and Food, \\ Central Veterinary Laboratory, Weybridge, Surrey
}

My cotic placentitis resulting from infection with various fungi is the cause of a substantial proportion of abortions affecting cattle. The fungus most frequently implicated in this country is Aspergillus fumigatus (Hugh-Jones and Austwick, 1967). However, little is known of the factors determining susceptibility and resistance to the sporadic infections produced by this organism in cattle.

Because of the problems associated with study of the natural disease in cattle, attempts have been made to reproduce the disease in smaller ruminants with a shorter gestation period. Although sheep are not subject to mycotic abortion under natural conditions, the disease has been produced experimentally in these animals (Cysewski and Pier, 1968). This has provided an experimental model which has been used at this laboratory to examine the immunological response to A. fumigatus during the course of infection in the pregnant animal.

At present, diagnosis of mycotic placentitis depends upon the microscopical detection of hyphae in placental lesions and recovery of the organism in culture. Mere isolation of an agent as ubiquitous as A. fumigatus does not establish the cause of the disease. Demonstration of a specific serological response to $A$. fumigatus might be of importance in distinguishing true infection from postabortion contamination.

\section{MATERIALS AND METHODS}

Strain of Aspergillus fumigatus. The isolate used, strain V. 10115, was originally cultured from the stomach contents of an aborted bovine foetus.

Sera. Rabbit antisera to strain V. 10115 were prepared by repeated subcutaneous and intramuscular injection of concentrated mycelial extracts emulsified in Freund's incomplete adjuvant. One batch of serum, RAf 2 , was used as a reference standard for antigen titration. This was preserved by the addition of 0.1 per cent. sodium azide and storage at $-20^{\circ} \mathrm{C}$.

Sheep. Twenty-two pregnant and three non-pregnant Suffolk-cross females were used. None had undergone a previous pregnancy. The animals were free from detectable disease and had not been used for any other experimental purpose. All were screened for precipitins to $A$. fumigatus before inoculation. The stage of gestation of the pregnant animals was estimated from the tupping date and subsequently confirmed by ultra-sonic screening.

Experimental design. The sheep were given intravenous injections of $2 \times 10^{7}$ viable conidia suspended in $10 \mathrm{ml}$ of $0.15 \mathrm{M} \mathrm{NaCl}$. Two groups of five animals were inoculated at the 30th and 100 th days of gestation, and three groups of four were inoculated at the 50th, 70th and 90 th days. A further inoculated group consisted of three non-pregnant animals.

Of the pregnant animals inoculated, all aborted except three inoculated at the 30th day

Received 14 Dec. 1972; accepted 27 Mar. 1973.

. MED. MICROBIOL.-VOL. 6 (1973) 
(nos. 1, 2, and 3) and one inoculated at the 100th day of gestation (no. 8). In each case the cause of abortion was established as $A$. fumigatus by microscopical and cultural examination of the placenta and foetal stomach contents.

Serum samples were collected from all sheep immediately before inoculation and at weekly intervals thereafter. All sera were stored at $-20^{\circ} \mathrm{C}$ until required.

Preparation of mycelial extract. Mycelium was produced by growing strain V. 10115 in stirred 800 -ml volumes of modified Czapek-Dox liquid medium at $37^{\circ} \mathrm{C}$ for $48 \mathrm{hr}$. The medium consisted of $3.0 \mathrm{~g} \mathrm{NaNO}_{3}, 0.5 \mathrm{~g} \mathrm{KCl}, 0.5 \mathrm{~g} \mathrm{MgSO}_{4} 7 \mathrm{H}_{2} \mathrm{O}$, and $0.01 \mathrm{~g} \mathrm{FeSO}_{4} 7 \mathrm{H}_{2} \mathrm{O}$, dissolved in $1000 \mathrm{ml}$ distilled water. To the solution, $30 \mathrm{~g}$ sucrose and $1.0 \mathrm{~g} \mathrm{~K}_{2} \mathrm{HPO}_{4}$ were added and the mixture was autoclaved at $10 \mathrm{lbf}$ per in ${ }^{2}$ for $15 \mathrm{~min}$. Penicillin and streptomycin were added to a final concentration of 20 and $40 \mu \mathrm{g}$ per ml, respectively, to maintain bacterial sterility. The final $p H$ was $7 \cdot 3$.

No detectable spores were present after growth for $48 \mathrm{hr}$. The cultures were collected, pooled and freed of extracellular products and growth medium by repeated centrifugation in de-ionised water at $4^{\circ} \mathrm{C}$. Washed mycelium was deposited by centrifugation, freed of excess water by squeezing between filter papers and disrupted by six cycles of freeze-pressing at $-25^{\circ} \mathrm{C}$ in an Edebo X-Press (Biotec, Croydon). Microscopical examination of the turbid grey liquid produced on thawing showed $>95$ per cent. disruption of cellular elements. This material was concentrated by counter-dialysis against polyethylene glycol $20 \mathrm{M}$ and clarified by centrifugation. The concentrate was used for serological tests and was standardised against a rabbit antiserum (RAf2) before use.

Serological methods. Immunodiffusion tests were performed essentially according to Ouchterlony (1953).

Complement-fixation tests were done according to a standard procedure with four 50 per cent. haemolytic doses of complement, a fixation period of $18 \mathrm{hr}$ at $4^{\circ} \mathrm{C}$ and five 50 per cent. haemolytic doses of haemolysin for sheep erythrocyte sensitisation. The antigen used was mycelial extract titrated to optimal titre against a rabbit serum (RAf2) under the same conditions. All reagents were employed in unit volumes of $0.1 \mathrm{ml}$. This method enabled complement-fixing antibodies to $A$. fumigatus to be detected in both sheep and rabbit sera. Earlier attempts with a method based on short fixation at $37^{\circ} \mathrm{C}$ were unsuccessful.

Immunoelectrophoresis was done according to Scheidegger (1955) in 1 per cent. Oxoid No. 1 Agar buffered to $p \mathrm{H} 8.6$ with barbital buffer $(I=0.05)$. Concentrated mycelial extract was used as antigen.

\section{RESULTS \\ Precipitation analysis of sera}

No sera from animals in the present study showed detectable precipitins to A. fumigatus before inoculation. It should be stressed however that we have previously encountered sera from apparently normal sheep giving 1-2 precipitation lines identical with those produced by sera from known infected animals.

Following the inoculation of $A$. fumigatus spores, precipitins to mycelial antigens usually became detectable in sheep sera after 1-2 wk. The precipitation patterns varied somewhat between animals, but in each case they tended to increase in complexity and intensity over the succeeding weeks.

Of five ewes inoculated at the 30th day of gestation, only one subsequently aborted from mycotic placentitis; the four non-aborting ewes (table I) produced detectable precipitins from the first week after inoculation and their precipitation patterns generally declined in intensity and complexity after the first few weeks and in each case precipitins were no longer detectable at the time of lambing. This decline in the amount of precipitin was probably not related simply to continuation of pregnancy, because, in the single ewe that failed to abort after 
inoculation at the 100th day of gestation (no. 8), the precipitins showed only a transient decline in the period preceding parturition (table I).

Table I shows that in the non-pregnant inoculated sheep, the precipitin response was more intense and more prolonged than in the non-aborting pregnant animals, thus resembling the response produced by ewes developing mycotic placentitis. In these animals (table II), the precipitation patterns

TABLE I

The precipitin response of ewes given inoculations of $A$. fumigatus spores without subsequent abortion

\begin{tabular}{|c|c|c|c|c|c|c|c|c|}
\hline \multirow{2}{*}{$\begin{array}{l}\text { Number } \\
\text { of days after } \\
\text { inoculation }\end{array}$} & \multicolumn{8}{|c|}{$\begin{array}{l}\text { Numbers of precipitation lines produced by sera from sheep } \\
\text { numbers }\end{array}$} \\
\hline & $\begin{array}{c}1 \\
(30)\end{array}$ & $\underset{(30)}{2}$ & $\stackrel{3}{3}$ & $\begin{array}{c}4 \\
(30)\end{array}$ & $\begin{array}{c}5 \\
(\mathrm{NP})\end{array}$ & $\begin{array}{c}6 \\
(\mathrm{NP})\end{array}$ & $\stackrel{7}{(\mathrm{NP})}$ & $\begin{array}{c}8 \\
(100)\end{array}$ \\
\hline $\begin{array}{r}0 \\
7 \\
14 \\
21 \\
28 \\
35 \\
42 \\
49 \\
56 \\
63 \\
70 \\
77 \\
84 \\
91 \\
98 \\
105 \\
112 \\
119 \\
126\end{array}$ & $\begin{array}{r}0 \\
2 \\
>2 \\
3 \\
>3 \\
>3 \\
2 \\
2 \\
2 \\
1 \\
1 \\
1 \\
1 \\
1 \\
1 \\
2 \\
2 \\
1 \\
1 \\
0^{*}\end{array}$ & $\begin{array}{l}0 \\
2 \\
1 \\
1 \\
1 \\
1 \\
1 \\
1 \\
1 \\
0 \\
0 \\
0 \\
0 \\
0 \\
0 \\
0 \\
0^{*} \\
1 \\
1\end{array}$ & $\begin{array}{r}0 \\
>\mathbf{2} \\
3 \\
>1 \\
>1 \\
1 \\
1 \\
1 \\
1 \\
1 \\
>2 \\
3 \\
3 \\
1 \\
1 \\
1 \\
1 \\
1 \\
1 \\
0^{*} \\
0\end{array}$ & $\begin{array}{r}0 \\
2 \\
1 \\
1 \\
>2 \\
1 \\
1 \\
1 \\
1 \\
>2 \\
>1 \\
>1 \\
>1 \\
1 \\
1 \\
1 \\
1 \\
0 \\
0 \\
0 * \\
0\end{array}$ & $\begin{array}{r}0 \\
0 \\
0 \\
1 \\
>2 \\
>2 \\
>2 \\
>3 \\
>3 \\
>3 \\
>3 \\
>3 \\
>3 \\
2 \\
\ldots \\
\ldots \\
\ldots \\
\ldots\end{array}$ & $\begin{array}{r}0 \\
>1 \\
>3 \\
>4 \\
>4 \\
>3 \\
>1 \\
>1 \\
>1 \\
>1 \\
>2 \\
>3 \\
>3 \\
>1 \\
\ldots \\
\ldots \\
\ldots \\
\ldots \\
\ldots\end{array}$ & $\begin{array}{r}0 \\
0 \\
>3 \\
>4 \\
>4 \\
>4 \\
>4 \\
>3 \\
>3 \\
>3 \\
>3 \\
>2 \\
\ldots \\
\ldots \\
\ldots \\
\ldots \\
\ldots \\
\ldots \\
\ldots\end{array}$ & 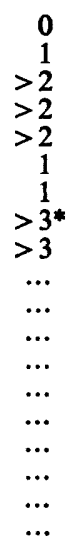 \\
\hline
\end{tabular}

Figures in parentheses indicate the day of gestation on which each ewe was inoculated. (NP) $=$ Not pregnant. $\ldots=$ Not done. * = Lambed.

generally increased in complexity and intensity for several weeks after their initial appearance and persisted in some instances for the duration of the observation period, although in most of the animals tested at the 12th wk the precipitins had declined.

All abortions occurred between the 3rd and 7th wk after inoculation (table II). There was no evidence that the interval between inoculation and abortion was influenced by the stage of gestation at which ewes were infected. Although the precipitin response usually achieved its greatest intensity and complexity near the time of abortion, some animals (e.g., nos. 15, 18 and 20) produced their maximum response some weeks after abortion.

The patterns produced by sera taken just before and just after abortion were closely examined for characteristics which could be related specifically to this event, but none was found. Although most sera shared some lines of precipitation, variations between samples from individual animals were apparent. 


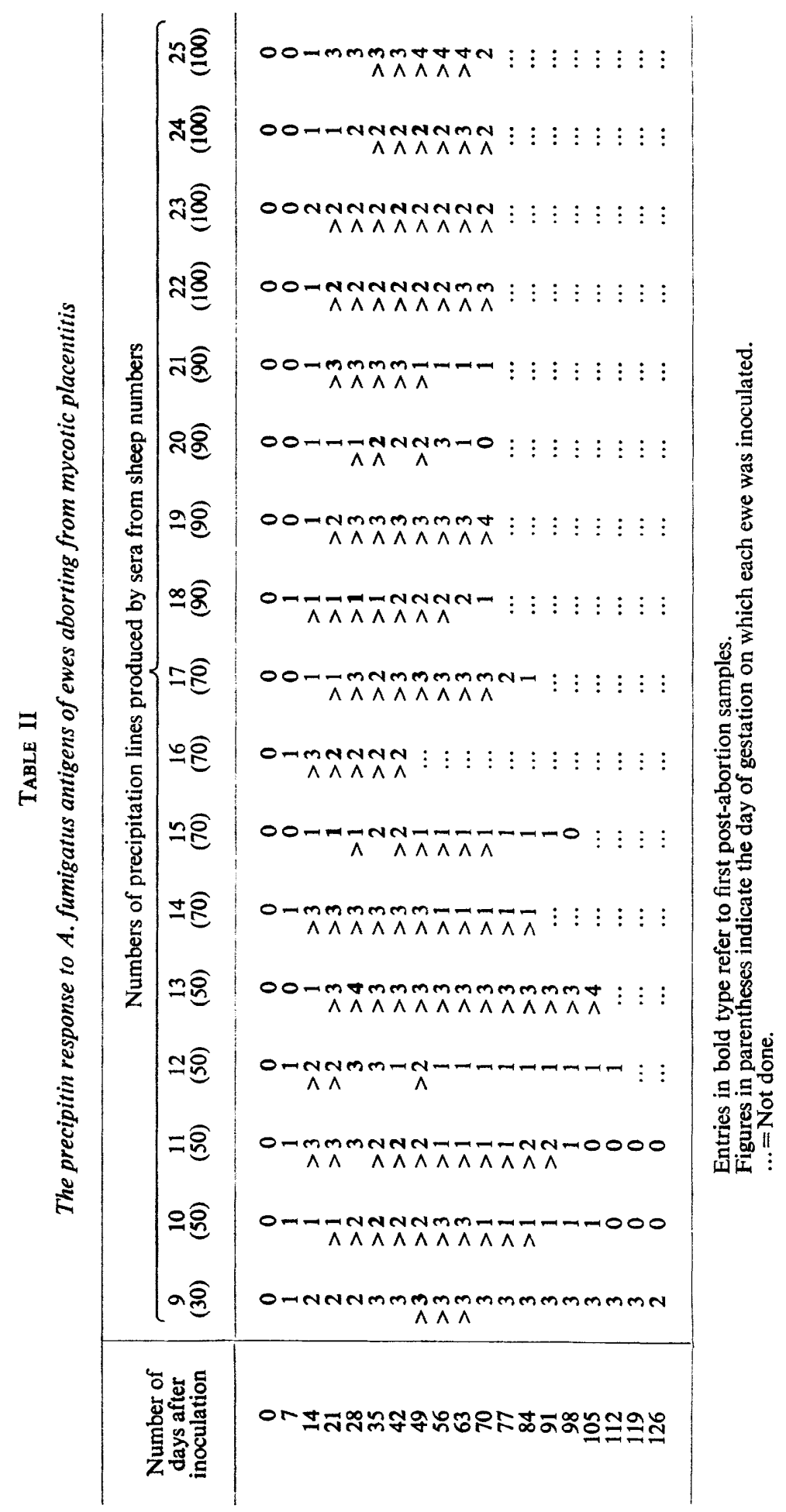


Immunoelectrophoretic analysis

In an attempt to resolve the precipitation patterns obtained with these sera into identifiable components, immunoelectrophoretic analysis was used. This confirmed the results of simple immunodiffusion, showing that an increasingly complex spectrum of precipitating antibodies developed after inoculation, but the method again failed to identify any individual component specifically
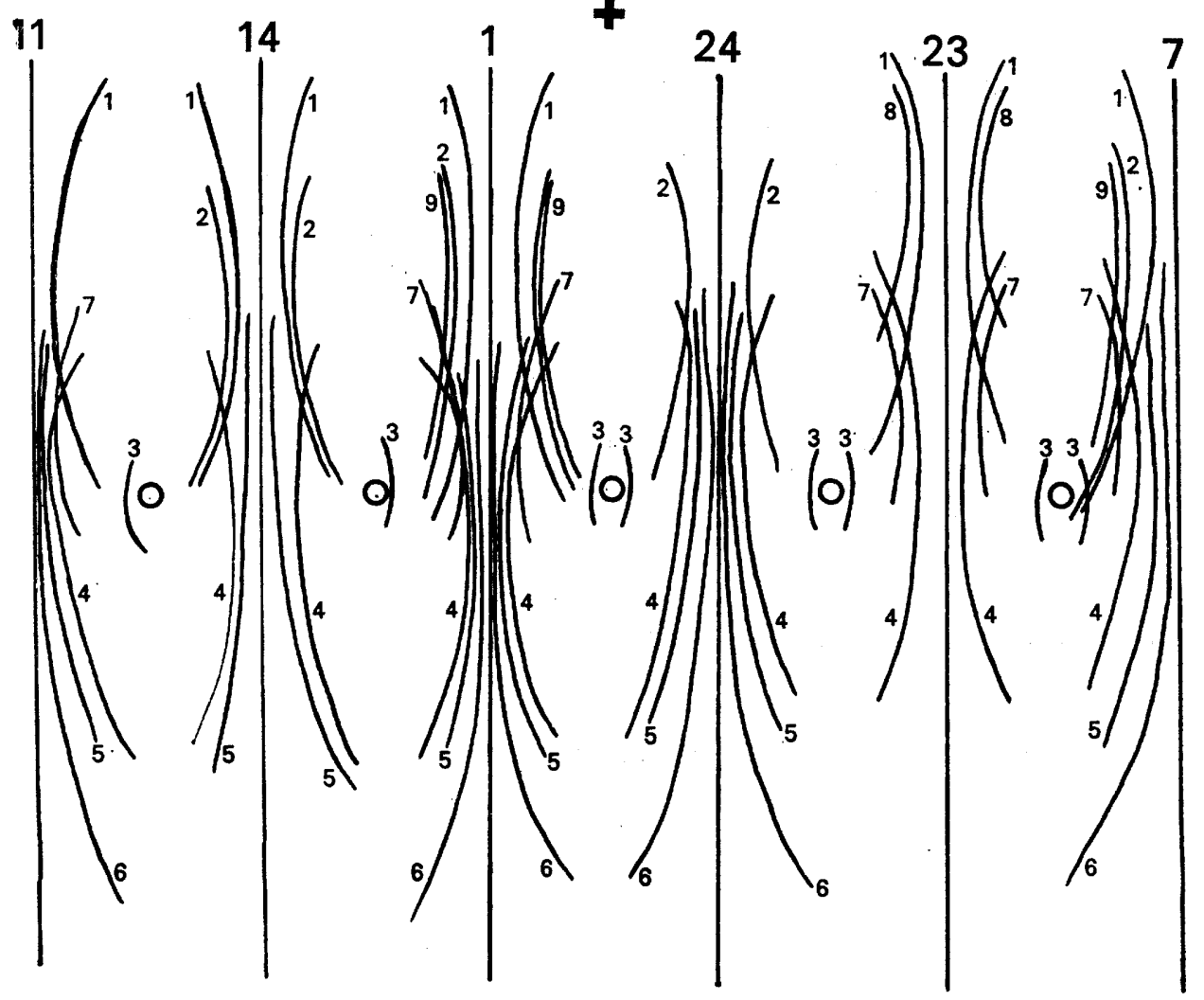

FIGURE-Immunoelectrophoresis of mycelial extract $(100 \mathrm{mg}$ per $\mathrm{ml})$ against sera from ewes no. $1,7,11,14,23$ and 24 at the height of the precipitin response to $A$. fumigatus.

associated with abortion. The results obtained with sera from six animals (nos. $1,7,11,14,23$ and 24) at the height of the precipitin response are illustrated in the figure, which shows all the variations in precipitation pattern encountered. In the figure, the distinct component lines are numbered and the frequency of their occurrence at different stages of infection in eight animals is summarised in Table III.

Components 1 and 4 appeared first, usually followed by component 7 . Components 3, 5 and 6 were produced only at the height of the response and developed only in a proportion of the sera. The most persistent precipitins were usually made up of components 1,2 and 7 . The most important components appeared to be $1,2,4$ and 7 . 


\section{TABLE III}

Immunoelectrophoretic analysis of precipitin reactions produced between A. fumigatus antigens and sera of ewes given inoculations of $A$. fumigatus spores

\begin{tabular}{|c|c|c|c|c|c|c|c|c|}
\hline \multirow{2}{*}{$\begin{array}{l}\text { Number } \\
\text { of days after } \\
\text { inoculation }\end{array}$} & \multicolumn{8}{|c|}{$\begin{array}{l}\text { Identities of precipitation arcs produced by } \\
\text { immunoelectrophoresis of sera from sheep numbers }\end{array}$} \\
\hline & $\begin{array}{c}1 \\
(30)\end{array}$ & $7^{7}$ & $\begin{array}{c}8 \\
(100)\end{array}$ & $\begin{array}{c}9 \\
(30)\end{array}$ & $\begin{array}{c}12 \\
(50)\end{array}$ & $\begin{array}{c}17 \\
(70)\end{array}$ & $\begin{array}{c}21 \\
(90)\end{array}$ & 25 \\
\hline $\begin{array}{r}0 \\
7 \\
14 \\
21 \\
35 \\
42\end{array}$ & $\begin{array}{c}0 \\
1,4 \\
1,4 \\
1,4,7 \\
1,4,7 \\
1,2\end{array}$ & $\begin{array}{c}0 \\
0 \\
1,4 \\
1,4,7 \\
1,4,7 \\
1,4,5,\end{array}$ & $\begin{array}{c}0 \\
1 \\
1,4 \\
1,4,7 \\
1 \\
2,3,4,\end{array}$ & $\begin{array}{c}0 \\
1 \\
1,4 \\
1,4 \\
1,4 \\
1,4,2\end{array}$ & $\begin{array}{c}0 \\
1 \\
1,4 \\
1,4 \\
1,4,2 \\
2\end{array}$ & $\begin{array}{c}0 \\
0 \\
1 \\
1 \\
1,4 \\
3,4,5 \text {, }\end{array}$ & $\begin{array}{c}0 \\
0 \\
1 \\
1,4,7 \\
1,4 \\
1,2\end{array}$ & $\begin{array}{c}0 \\
0 \\
1 \\
1,4,7 \\
1,4,7 \\
1,4,5,\end{array}$ \\
\hline 56 & 2 & 1,4 & $1,2,4$ & $1,2,3$, & 2 & $1,2,4$ & 2 & $1,2,3$, \\
\hline $\begin{array}{r}70 \\
84 \\
126\end{array}$ & $\begin{array}{l}2 \\
2 \\
0\end{array}$ & $\begin{array}{l}1,2 \\
\cdots \\
\cdots\end{array}$ & $\begin{array}{l}\cdots \\
\cdots \\
\cdots\end{array}$ & $\begin{array}{l}1,2 \\
2\end{array}$ & $\begin{array}{c}2 \\
2 \\
\cdots\end{array}$ & $\begin{array}{c}1,2,7 \\
7 \\
\cdots\end{array}$ & $\begin{array}{l}2 \\
\cdots \\
\cdots\end{array}$ & $\begin{array}{l}1,2 \\
\cdots \\
\cdots\end{array}$ \\
\hline
\end{tabular}

The precipitation arcs, numbered 1-7, are those illustrated in the figure.

Entries in bold type refer to first post-abortion samples.

Figures in parentheses indicate the day of gestation on which each ewe was inoculated.

(NP) $=$ Not pregnant. $\quad \ldots=$ Not done.

TABLE IV

The production of complement-fixing antibodies by ewes given inoculations of $A$. fumigatus spores without subsequent abortion

\begin{tabular}{|c|c|c|c|c|c|c|c|}
\hline \multirow{2}{*}{$\begin{array}{l}\text { Number } \\
\text { of days after } \\
\text { inoculation }\end{array}$} & \multicolumn{7}{|c|}{$\begin{array}{l}\text { Reciprocal titres of complement fixing antibodies in sera of } \\
\text { sheep numbers }\end{array}$} \\
\hline & $\begin{array}{c}1 \\
(30)\end{array}$ & $\begin{array}{c}2 \\
(30)\end{array}$ & $\begin{array}{c}3 \\
(30)\end{array}$ & $\begin{array}{c}4 \\
(30)\end{array}$ & $\begin{array}{c}6 \\
(\mathrm{NP})\end{array}$ & $\begin{array}{c}7 \\
\text { (NP) }\end{array}$ & $\begin{array}{c}8 \\
(100)\end{array}$ \\
\hline $\begin{array}{r}0 \\
7 \\
14 \\
21 \\
28 \\
35 \\
42 \\
49 \\
56 \\
63 \\
70 \\
77 \\
84 \\
91 \\
98 \\
105 \\
112 \\
119 \\
126\end{array}$ & $\begin{array}{l}10 \\
20 \\
20 \\
20 \\
20 \\
20 \\
20 \\
20 \\
20 \\
20 \\
20 \\
20 \\
20 \\
20 \\
10 \\
<2 \\
<2 \\
<2 \\
<2 *\end{array}$ & $\begin{array}{c}4 \\
10 \\
10 \\
10 \\
10 \\
10 \\
10 \\
10 \\
10 \\
10 \\
20 \\
20 \\
20 \\
20 \\
4 \\
4 \\
4^{*} \\
20 \\
20\end{array}$ & $\begin{array}{l}<2 \\
20 \\
10 \\
40 \\
40 \\
40 \\
40 \\
40 \\
40 \\
40 \\
20 \\
20 \\
10 \\
10 \\
10 \\
<2 \\
<2 \\
<2 * \\
10\end{array}$ & $\begin{array}{c}20 \\
10 \\
10 \\
10 \\
10 \\
10 \\
10 \\
10 \\
10 \\
10 \\
10 \\
10 \\
10 \\
4 \\
10 \\
4 \\
4 \\
10 * \\
10\end{array}$ & $\begin{array}{r}<2 \\
2 \\
20 \\
20 \\
20 \\
10 \\
10 \\
10 \\
10 \\
10 \\
20 \\
10 \\
4 \\
\ldots \\
\ldots \\
\ldots \\
\ldots \\
\ldots \\
\ldots\end{array}$ & $\begin{array}{r}<2 \\
<2 \\
10 \\
2 \\
2 \\
2 \\
4 \\
10 \\
20 \\
2 \\
\ldots \\
\ldots \\
\ldots \\
\ldots \\
\ldots \\
\ldots \\
\ldots \\
\ldots \\
\ldots\end{array}$ & $\begin{array}{c}<2 \\
<2 \\
<2 \\
<2 \\
20 \\
4 \\
10 \\
10^{*} \\
10 \\
\ldots \\
\ldots \\
\ldots \\
\ldots \\
\cdots \\
\ldots \\
\ldots \\
\ldots \\
\ldots\end{array}$ \\
\hline
\end{tabular}

Footnotes as in table I.

No serum available for sheep number 5 . 


\section{Complement-fixation reaction}

The main disadvantages of immunodiffusion methods are their relative insensitivity and their virtually non-quantitative nature. To determine whether a rising titre could be used as an indicator of active infection, the complementfixation test was examined.

Unlike the immunodiffusion test, the complement-fixation test showed significant titres in the pre-inoculation sera of some animals (nos. 1 and 4 in table IV; no. 9 in table V). Following inoculation, nearly all sera showed a rise in titre. In sheep nos. 9 and 10 (table V) the titres underwent a decrease just before abortion occurred. Sometimes the titre rose to higher values 7-10 days after abortion (e.g., nos. 17, 23, 24). In general, titres declined irregularly over the succeeding weeks. A few animals showed erratic rises in titre after a period of decline (e.g., nos. 10 and 15) possibly as a result of anamnestic response to environmental exposure.

Table IV shows that there was little difference in the maximum titres produced by non-aborting and non-pregnant sheep, but the titres of the latter appeared to decline more rapidly. In the aborting group (table V) there was considerable variation between the titres produced by individual animals, but those inoculated early in pregnancy tended to produce higher titres than those inoculated at the 90th or 100th day of gestation. In each case antibodies persisted at detectable levels for some weeks after abortion. There was no obvious relationship between the magnitude of the complement-fixation titres and the precipitation patterns produced by the sera.

\section{Discussion}

The object of this study was to examine the serological response to $A$. fumigatus in the ovine experimental model for mycotic abortion.

Although sheep are not subject to mycotic abortion under natural conditions, the disease is readily produced experimentally and, allowing for differences in placentation and gestation period, resembles the natural infection in cattle (Cysewski and Pier, 1968). The serological changes occurring in this experimental infection were of interest because of their possible relevance to the diagnosis of mycotic abortion in cattle.

An extract of actively growing $A$. fumigatus mycelium was used as antigen because it was considered that it would give a more specific indication of active infection than preparations containing spore antigens. It seemed reasonable to assume that environmental exposure to $A$. fumigatus would consist primarily of contact with spores which, in immunological competent individuals, would be eliminated either before or shortly after germination occurred.

In studies of human sera, Longbottom and Pepys (1964) and Amos (1970) observed that an appreciable number of individuals without clinical evidence of aspergillosis possessed antibodies to A. fumigatus extracts. However, the antigen preparations used were derived from sporulating mycelium. In the present study no precipitins to $A$. fumigatus were detected in pre-inoculation sera, although an appreciable number of animals had complement-fixing antibodies. 


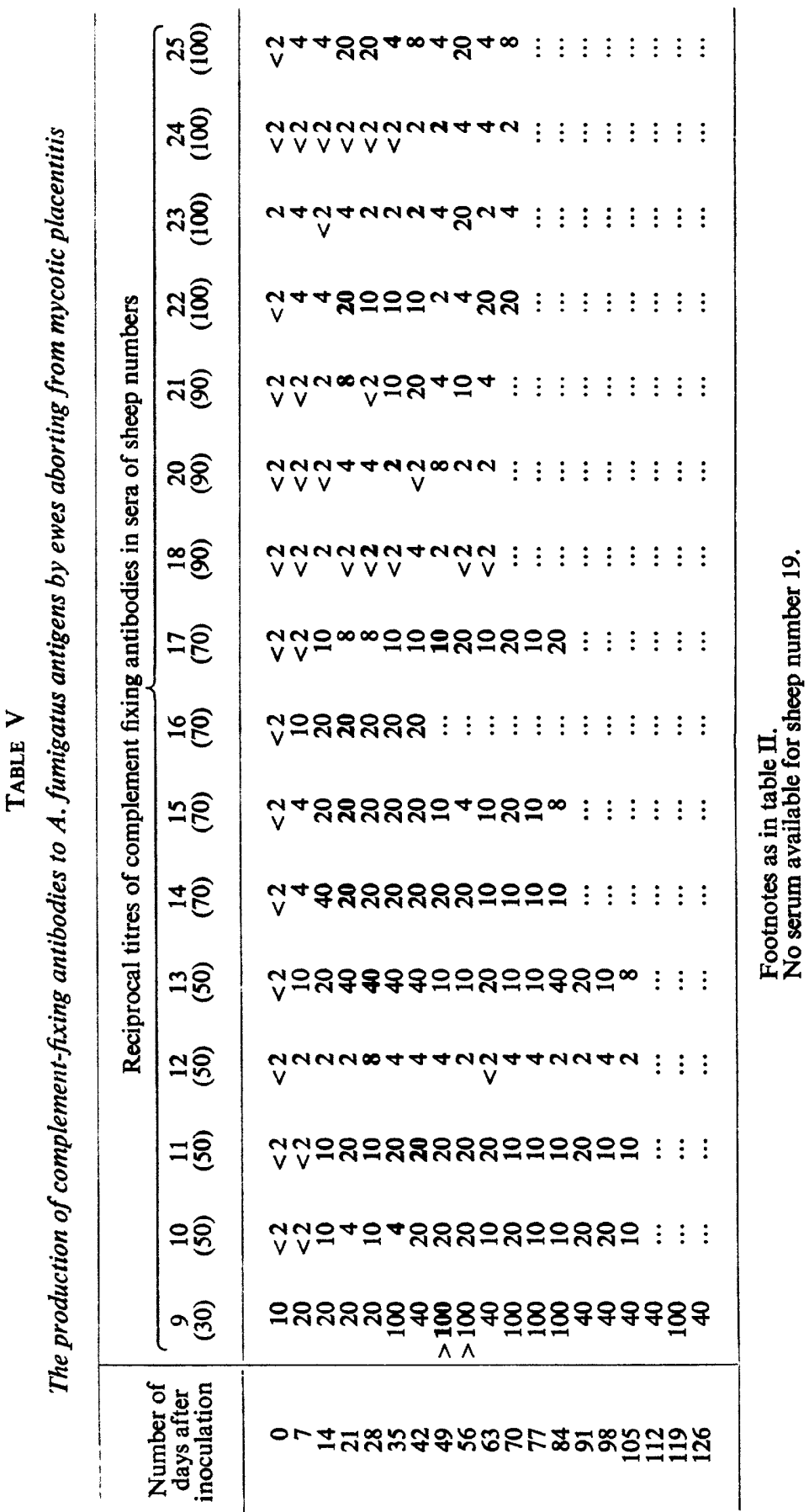


The immunodiffusion studies gave positive results in pregnant ewes inoculated with $A$. fumigatus spores and were in agreement with the recent results of Thurston et al. (1972). However, the method gave no promise of being useful to predict imminent abortion, because the precipitation patterns of serum samples from aborting animals showed no characteristic features and their response resembled that produced by inoculated non-pregnant animals.

The immunoelectrophoretic results showed that, although in most animals the same spectrum of antibodies to $A$. fumigatus was produced, the components did not always develop in the same order and again no particular pattern could be associated with imminent abortion. The persistence of precipitating antibodies for at least several months following abortion means that it might be difficult to distinguish past infection from present infection by this method.

The rapidity with which precipitins sometimes became detectable after inoculation of ewes suggested an anamnestic response, possibly resulting from previous environmental exposure to A. fumigatus or closely related fungi.

The results of the complement-fixation tests showed that titres sometimes fluctuated at about the time of abortion, but fluctuation also occurred at other times and thus it could not be used to predict abortion.

In the weeks following abortion the complement-fixation titres generally declined although sporadic rises occurred. On the other hand, immunoprecipitation patterns usually continued to increase in complexity for some time after abortion before starting to decline.

These results indicate that both immunodiffusion and complement-fixation procedures could be used to detect antibodies to $A$. fumigatus in infected animals. However, the presence of antibodies to $A$. fumigatus antigens has no specific diagnostic value for placental infection. In this respect, the development of antibodies to isologous placental antigens (Corbel, 1972a) appears more significant. Parallel studies should be conducted in cattle before any conclusions are drawn as to the applicability of these findings to that species.

Recent observations have been made (Corbel, 1972b) on the presence of precipitins to A. fumigatus in the sera of field cases of mycotic abortion. Although frequently present in the sera of cows aborting from infection with $A$. fumigatus or closely related aspergilli, precipitins were rarely encountered in cows with no history of mycotic abortion. Further studies have failed to detect precipitins to $A$. fumigatus in the sera of 164 cows aborting from causes other than fungal infection (Corbel, to be published). Thus, preliminary results suggest that the serological response of cattle to A. fumigatus is not dissimilar to that of experimentally inoculated sheep.

\section{SUMMARY}

The serological response to Aspergillus fumigatus in experimental mycotic abortion in sheep was examined. Infected ewes developed precipitins and complement-fixing antibodies to $A$. fumigatus mycelial antigens following the inoculation of spores. A gradual increase in complexity of the precipitation patterns given by immunodiffusion tests extended over several months and overlapped the times of abortion, but precipitins to individual $\boldsymbol{A}$. fumigatus 
antigens could not be specifically associated with placentitis or abortion. Following abortion, the precipitation patterns decreased in complexity, although in most cases some activity persisted. Complement-fixing antibodies also developed before abortion and erratically declined in the post-abortion period.

The authors wish to thank Mrs C. A. Day, AIMLT and Mr D. J. W. Cole for excellent technical assistance.

\section{REFERENCES}

Amos, W. M. G. 1970. The extraction of fungal antigens and their use in serological tests as an aid to the diagnosis of bronchial disorders. J. Med. Lab. Technol., 27, 18.

Corbel, M. J. 1972a. Production of antibodies to placental antigens by pregnant ewes experimentally infected with Aspergillus fumigatus. Br. Vet. J., 128, xliv.

CORBEL, M. J. 1972b. The serological response to Aspergillus fumigatus antigens in bovine mycotic abortion. Br. Vet. J., 128, lxxiii.

CYSEwSKi, S. J., AND PIER, A. C. 1968. Mycotic abortion in ewes produced by Aspergillus fumigatus: pathologic changes. Am. J. Vet. Res., 29, 1135.

Hugh-Jones, M. E., AND Austwick, P. K. C. 1967. Epidemiological studies in bovine mycotic abortion. I. The effect of climate on incidence. Vet. Rec., 81, 273.

Longbotrom, J. L., AND PePYs, J. 1964. Pulmonary aspergillosis: diagnostic and immunological significance of antigens and C-substance in Aspergillus fumigatus. J. Path. Bact., 88,141 .

OUCHTERLONY, O. 1953. Antigen-antibody reactions in gels. Acta path. microbiol. scand., $32,231$.

SCheidegGer, J. J. 1955. Une microméthode de l'immunoelectrophorèse. Int. Archs. Allergy Appl. Immun., 7, 103.

Thurston, J. R., Cysewskı, S. J., Pier, A. C., ANd Richard, J. L. 1972, Precipitins in serums from sheep infected with Aspergillus fumigatus. Am. J. Vet. Res., 33, 929. 